\title{
LITIOFORITAS DO DISTRITO MANGANÍFERO ARACOIABA-PACAJÚS, CEARÁ E DE ITAPIRA, SÃO PAULO
}

\author{
E.Ribeiro Filho ${ }^{1}$ \\ N.Angeli ${ }^{2}$ \\ J.V.de Souza ${ }^{3}$
}

A litioforita, um óxido aluminoso de manganês, tem sido identificada em solos e em depósitos de manganês formados por laterização.

Nestes depósitos lateríticos as litioforitas apresentam uma fase intermediária no processo de enriquecimento supérgeno a que ficam sujeitos protominérios silicáticos e/ou sílico-carbonáticos, tais como aqueles que ocorrem na Serra do Navio, em Lafaiete, no Ceará e em Itapira.

Constitui exceção a litioforita do distrito de Postmasburg, na África do Sul, descrita como de origem hidrotermal. Atualmente admite-se que existe um grupo de litioforitas com fórmula geral:

$$
\mathrm{m}\left[\left(\mathrm{Al}_{0,5} \mathrm{Li}_{0,5}\right) \mathrm{MnO}_{2}(\mathrm{OH})_{2}\right] \mathrm{n}\left[\mathrm{Al}_{0,667}\left(\mathrm{Mn}^{+4}, \mathrm{Co}^{+2}, \mathrm{Ni}^{+2}, \mathrm{Mn}^{+2}\right) \mathrm{O}_{2}(\mathrm{OH})_{2}\right] \mathrm{pH}_{2} \mathrm{O}
$$

Os elementos de transição, $\mathrm{Co}, \mathrm{Ni}, \mathrm{Cu}$ e $\mathrm{Zn}$ podem entrar na composição das litioforitas, de um modo ainda não explicado definitivamente.

A litioforita é de fácil identificação em seções polidas, em decorrência de suas propriedades opticas bem definidas, bem como quando submetida à análise em raios-X, em conseqüência de sua estrutura cristalina. Embora tenha sido estudada em amostras

\footnotetext{
${ }_{1}$ Departamento de Geologia Econômica e Geofísica Aplicada, Instituto de Geociências/USP, São Paulo. 2 UNESP, Rio Claro.

${ }^{3}$ UFCE, Ceará.
} 
provenientes da Saxônia, África, União Soviética, Austrália, Estados Unidos, Nova Caledônia e Brasil, ainda pairam dúvidas quanto a dois aspectos referentes à sua composição química. A primeira refere-se ao conteúdo em lítio, razão do nome do mineral, ainda que algumas das litioforitas estudadas não o contenham, posto que a amostra de Schneeberg, Saxônia, continha $1,23 \%$ de $\mathrm{Li}_{2} \mathrm{O}$. A segunda refere-se ao conteúdo de $\mathrm{Cu}, \mathrm{Ni}$, $\mathrm{Co}$ e $\mathrm{Zn}$ em algumas das litioforitas descritas na literatura. Estes elementos de transição contidos nas litioforitas teriam seus teores dependentes do tipo de paragênese, e como tais seriam importantes na caracterização tanto do protominério quanto da evolução dos processos de enriquecimento supérgeno.

No Brasil já foram estudadas litioforitas de Lafaiete, Minas Gerais; Marau, Bahia; Serra do Navio, Amapá; Manganês do Azul, Carajás; Buritirama, Pará; Aracoiaba Pacajús, Ceará e Itapira, São Paulo. Em todas estas ocorrências brasileiras a litioforita está associada a protominérios silicáticos e sílico-carbonáticos, ricos em espessartita, nos quais é tida como um mineral de transição durante o processo de concentração de óxidos de manganês.

Acredita-se que quando as litioforitas constituem uma fase de transição entre a transformação de espessartita para óxidos de manganês do tipo a $\mathrm{MnO}_{2}$, seus teores em elementos de transição são muito baixos. Por outro lado, quando as espessartitas geram predominantemente a $\mathrm{MnO}_{2}$ (criptomelana) e poucas lamelas de litioforita os teores em elementos de transição são elevados.

As litioforitas dos depósitos de manganês de Fiuza 1, 2 e 3 e de Aldeia ocorrem em corpos lenticulares de protominérios e/ou minérios intercalados em seqüências de granada-quartzitos e de gnaisses, localizados no distrito manganífero de Aracoiaba-Pacajús, no Ceará.

As litioforitas de Itapira, São Paulo, ocorrem em corpo lenticular de protominério e/ou minério silicático constituído de espessartita-quartzito, intercalado em ortognaisses do Grupo Amparo.

O estudo de litioforitas destes dois distritos manganíferos tem os seguintes objetivos:

1 - Caracterização mineralógica das litioforitas, trabalho já executado por análise microscópica de seções polidas e por raios-X. A textura de protominério/minério é granoblástica e bandada, com foliação evidente principalmente nas camadas de quartzo e nas lamelas de litioforita. A litioforita está sempre associada a cristais xenomorfos de espessartita, que se apresentam fraturados, arredondados e parcialmente intemperizados. A alteração de litioforita em oxidos do grupo $\mathrm{MnO}_{2}$ varia de incipiente a muito pronunciada. 
2 - Estudo da paragênese dos minerais dos minérios e protominérios, trabalho parcialmente elaborado.

3 - Estudo comparativo da composição das litioforitas, principalmente quanto aos teores de $\mathrm{Li}_{2} \mathrm{O}$ e dos elementos de transição. Trabalho em andamento.

4 - Interpretação do significado genético das litioforitas dos distritos Aracoiaba-Pacajús e Itapira.

5 - Estudo da possível relação entre os teores dos elementos de transição com os processos de formação da litioforita.

Análises qualitativas por microssonda revelaram a presença de traços de $\mathrm{Cu}$, $\mathrm{Ni}$ e Co, o que confirma a idéia de que nestas jazidas as litioforitas constituem fase de transição entre espessartitas e a criptomelana.

Nas jazidas estudadas ocorreram as transformações mineralógicas ilustradas na Figura 1.

\section{REFERÊNCIAS BIBLIOGRÁFICAS}

BEAUVAIS, A.; MELFI, A.; NAHON, D.; TRESCASES, J.J. (1987) Pétrologie du gisement latéritique manganésifère d'Azul (Brésil). Mineralium Deposita, 22(2):124-134.

GIAVONOLI, R. \& PERSEIL, E.A. (1985) Étude comparative des lithiophorites de synthèse et des lithiophorites de la zone d'oxydation des gisements ferro-manganésifères. Schweizrische Mineralogische und Petrographische Mitteilungen 65:9-27.

OSTWALD, J. (1984) Two varieties of lithiophorite in some Australian deposits. Mineralogical Magazine, 48(3):383-388.

PERSEIL, E.A. (1986) Signification génétique de la lithioforite dans le gisement manganésifère de la Serra do Navio, Brésil. The Canadian Mineralogist, 24(3):461-468.

MITCHELL, R.S. \& MEINTZER, R.E. (1967) Lithiophorite from Charlottesville, Virginia. American Mineralogist, 52(9-10):1545-1549.

PETERS, T.; VALARELLI, J.S.; COUTINHO, J.M.V.; SOMMERAUER, J.; RAUMER, J. 
Von (1977) The manganese deposits of Buritirama (Pará, Brazil). Schweizerische Mineralogische und Petrographische Mitteilungen, 57(3):313-327.

RIBEIRO FILHO, E. \& ANGELI, N. (1987) Litioforita no protominério e no minério de manganês de Itapira, SP: In: SIMPÓSIO REGIONAL DE GEOLOGIA, 6., Rio Claro, 1987. Boletim de Resumos. Rio de Janeiro, SBG. p.33-34.

SCOTT, K.M. (1987) Significance of a lithiophorite interface between cryptomelane and florencite. American Mineralogist, 72(3-4):429-432.

SOUZA, J.V. \& RIBEIRO FILHO, E. (1983) Geologia e gênese dos depósitos de manganês da província de Aracoiaba-Pacajús, Ceará. Boletim IG, 14:1-11.

VALARELLI, J.V. (1975) La lithiophorite de la Serra do Navio, Amapá, Brésil. Bol. Suisse Mineral. Petrograf., 55:19-30.

WADSLEY, A.D. (1952) The structure of lithiophorite (Al, Li) $\mathrm{MnO}_{2}(\mathrm{OH})_{2}$. Acta Crystallographica, 5:676-680. 


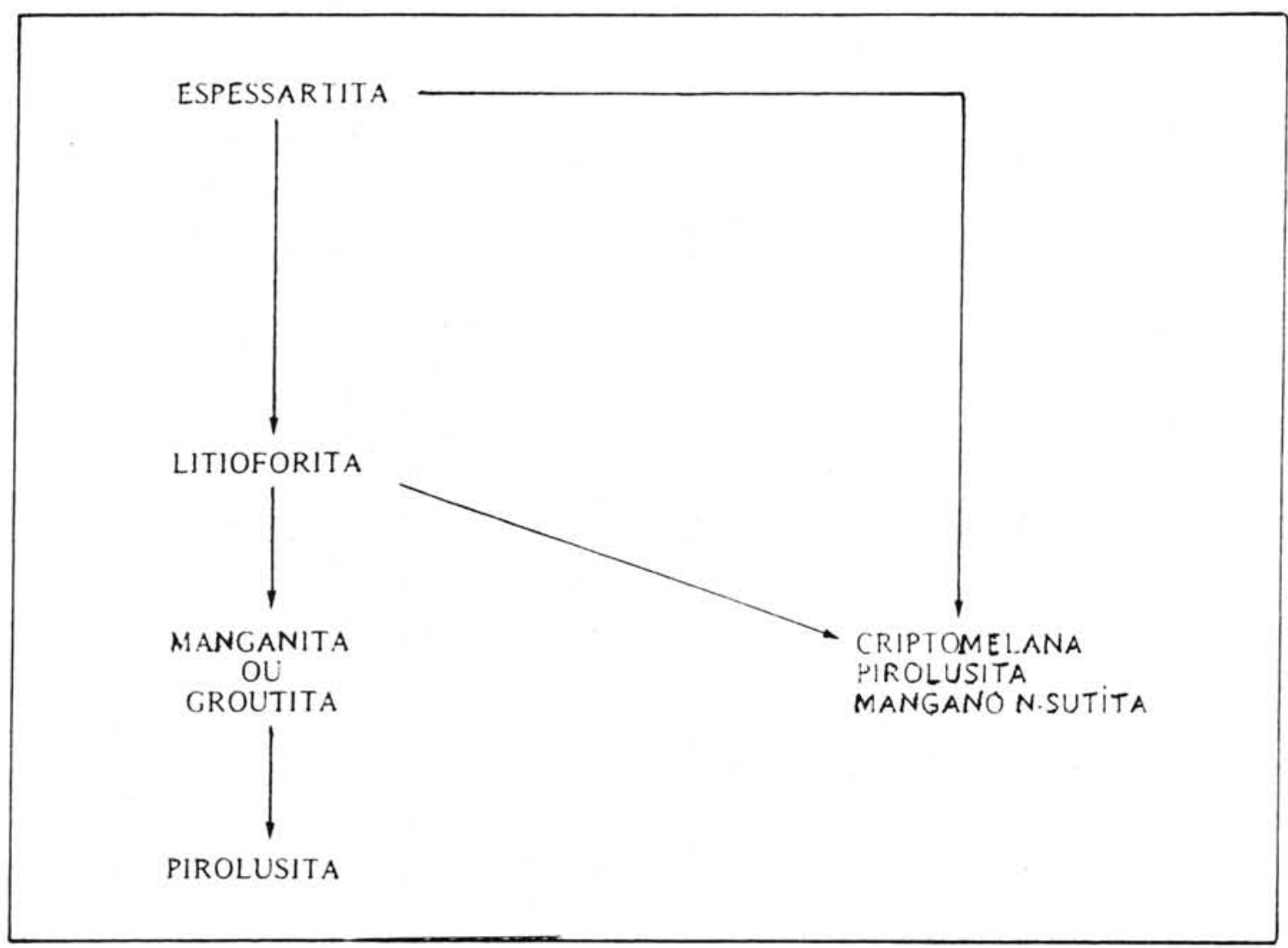

Figura 1 - Seqüência de formação dos minerais de manganês de Aracoiaba-Parajús e Itapira. 